\title{
EFFECT OF DYNAMIC VISCOSITY ON NANOFIBER DIAMETERS AND ELECTRICAL CONDUCTIVITY OF POLYACRYLONITRILE NANOFIBERS DOPED NANO-CU PARTICLES
}

\author{
Olivier M. Mpukuta ${ }^{1}$, Kevser Dincer ${ }^{* 1}$, Ilkay Özaytekin ${ }^{1}$ \\ ${ }^{1}$ Konya Technical University, Engineering and Natural Sciences Faculty, Department of Mechanical Engineering, Turkey
}

\begin{abstract}
Original scientific paper In this study, pure polyacrylonitrile (PAN) nanofibers in the diameter range of 200-500 nm and PAN/Cu composite nanofibers in 200-600 $\mathrm{nm}$ diameter range were produced at applied voltage of $15 \mathrm{kV}$. The distribution of fiber diameters, the dynamic viscosities of the solutions and the electrical conductivity (EC) of the produced fibers were examined as a function of copper nanoparticles content (1\%, 3\% and 5\% by weight). The dynamic viscosity of the electrospinning solution was an important parameter on the nanofiber morphology as well as on the nanofiber diameter distribution. Taken together, the data analysis showed that the highest EC value was $38 \times 10^{-2} \mathrm{~S} / \mathrm{cm}$, which was obtained from nanofibers produced by electrospinning solution containing $\% 1$ $\mathrm{Cu}$ nanoparticle having a dynamic viscosity value of $577.7 \mathrm{mPa}$.s. The addition of $\mathrm{Cu}$ nanoparticles increased the EC of pure PAN nanofibers by a factor of 2.37. In addition, further analysis of pure PAN nanofibers and \%1 Cu/PAN nanofibers were performed by XRD, contact angle and TGA devices. Results showed that the TGA degradation curves of both pure PAN and Cu-based PAN nanofibers presented the same behavior. In DSC analysis, the glass transition temperature of pure PAN nanofibers was observed at $112^{\circ} \mathrm{C}$, while no glass transition temperature was observed for PAN nanofibers containing $1 \% \mathrm{Cu}$.
\end{abstract}

Keywords: Copper nanoparticles, Electrical conductivity, Electrospinning, Nanofibers, Thermal stability

\section{Introduction}

Nowadays, fabrication of nanofibers containing nanoparticles is attracting widespread interest due to the fact that the resultant composite fibers take advantage of the outstanding properties of each component [1-3]. Nanofibers have very fine diameters and perfect pore interconnectivity. For this reason, they have extremely high specific surface area and porous structure. Composite nanofibers may provide solutions to both technological and environmental areas, such as solar energy conversion, electronic, filtration, protective textiles, biotechnology, biomedical sciences and so on [3, 4].

General production techniques such as drawing, phase separation, self-assembly, template synthesis, chemical vapor deposition, wet chemical synthesis and electrospinning have been used in the production of nanofibers in recent years [5]. It is worth noting that, among these methods, electrospinning has been studied widely because of its efficiency, simplicity, low cost and allows the preparation of continuous fibers with diameters down to a few nanometers as well $[4,6,7]$. What is more, various one-dimensional nanostructured materials such as metals, metal oxides, hydrocarbons, composites and so forth can be fabricated by electrospinning process [7]. Electrospinning is fundamentally different from air or other mechanically driven spinning techniques in that the extrusion force is a consequence of the interaction between the external applied electric field and the charged polymer [8]. The phenomenon is such as a high voltage applied on the solution leads to a highly charged polymer fluid, which in its turn allows the solution droplet at the tip to experience two main types of forces, the surface tension and the electrostatic repulsion force. When the charges in the solution reach the critical amount, an elongated cone called Taylor cone will be formed with the effect of its voltage. If the threshold voltage is above, an electrospinning jet is emitted. As the tension increases, the micro-dripping and intermittent jet becomes the Taylor cone jet. The electrospinning jet will travel towards the region of lower potential referred as collector and becomes narrower in the process [8,9]. Although the setup for electrospinning looks extremely simple, the physics behind it is very complex and involves the understanding of some notions such as fluid rheology, electrostatics and polymer solution [9]. The electrospinning process is controlled by many parameters, which can influence the transformation of polymer solutions into nanofibers. These parameters are mainly consisted of three categories: solutions parameters, governing variables and ambient parameters. Solution parameters include viscosity, conductivity, molecular weight, molecular weight distribution, elasticity, and surface tension. Process parameters include electric potential at the capillary tip, hydrostatic pressure in the capillary tube, flow rate and concentration, and the gap (distance between the tip and the collecting screen). Ambient parameters include temperature, humidity, and the air velocity in the electrospinning chamber $[5,8,10]$. It was reported that since all these parameters significantly 
affect the morphology and structure of the as-spun nanofibers, it is possible to obtain nanofibers with the desired diameter and morphology by controlling these parameters $[8,11]$. For instance, it was reported that the viscoelasticity of the solution, charge density carried by the jet, and the surface tension of the solution are the key factors that influence the formation of the beaded fibers. The increase in viscosity only supports bead-free fiber formation, while the increase in net charge density supports both bead-free fiber formation and finer fiber formation. Reducing surface tension also promotes beadfree fiber formation [12]. Another statement is fibers with a finer diameter can be obtained by reducing the concentration of the polymer in the solution [13].

In recent years, different combinations of polyacrylonitrile (PAN) polymers and nanoparticles were used to fabricate composite nanofibers for different purposes. Among them, PAN/ $\mathrm{SiO}_{2}, \mathrm{PAN} / \mathrm{TiO}_{2}$ and $\mathrm{PAN} / \mathrm{Bi}_{2} \mathrm{O}_{3}$ electrospun nanofibers were fabricated and their physical properties were examined [14], $\mathrm{PAN} / \mathrm{AgNO}_{3}$ were used to prepare fibrous membranes with antibacterial activity [15], $\mathrm{PAN} / \mathrm{ZnO}$ and $\mathrm{PAN} / \mathrm{Fe}_{2} \mathrm{O}_{3}$ nanofibers have been used to detect carbon dioxide [16]. It was reported that by using PAN nanofibers coated with a thin layer of conjugated polymer it was possible to detect explosive 2, 4, 6- trinitrotoluene (TNT) vapor [17, 18] and so on. But to the best of our knowledge, there is a lack of significant studies on EC of electrospun PAN fibers containing copper nanoparticles in the open literature. Therefore, in this study, the effect of dynamic viscosity of $\mathrm{Cu}$-based electrospinning solutions on the diameter and EC of the produced fibers has been investigated. Thermal degradation, surface contact angle and crystallinity structure of PAN nanofibers of the highest EC value were also performed. The produced materials can be used for various applications such as sensor devices, solar cells, PEM fuel cells and so on.

\section{Experimental}

\subsection{Materials}

Polyacrylonitrile powder (PAN, Mw $=150,000 \mathrm{~g} / \mathrm{mol})$ and N, N- Dimethylformamide anhydrous, (DMF, 99.8 $\%)$ were purchased from Sigma-Aldrich Co. Copper $(\mathrm{Cu}$, $25 \mathrm{~nm}, 99.9 \%$ ) was provided from Nanografi Co. Ltd. The chemicals provided in this study were used without purification.

\subsection{Fabrication of pure PAN and PAN/Cu Nanofibers}

The obtained solutions were stirred in the similar conditions as it has been done for pure PAN solutions. Finally, the solutions were poured into syringes. The following Figure 1 illustrate the procedure of the electrospinning solutions preparation.

The electrospinning setup consisted of a syringe pump, nanofiber collector and a power supply. The solution was held in a horizontal syringe with a stainless steel needle. The stainless steel needle was connected to an electrically positive high voltage power supply, while the metallic disk used as the fiber collector was connected to an electrically the negative high voltage power supply. For electrospinning, the distance between the collector and the needle was set to $12 \mathrm{~cm}$. The volumetric flow rate of the solution was maintained at $2.5 \mathrm{~mL} / \mathrm{h}$ using a digitally controlled syringe pump for each copper content in solutions of nanofibers were performed at $15 \mathrm{kV}$.

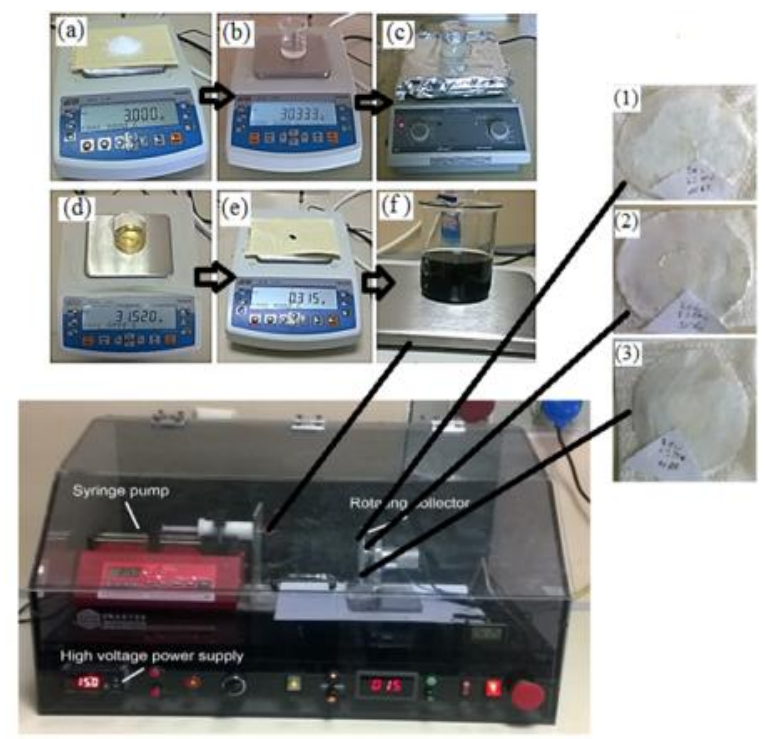

Figure 1. Preparation electrospinning solution for PAN nanofibers with CuNPs (a) PAN, (b) DMF, (c) Steering of PAN/DMF mixture, (d) PAN/DMF solutions after steering, (e) CuNPs (f) mixture of PAN/DMF/CuNPs after steering process (1) PAN nanofibers with $1 \mathrm{wt}$ $\%$ CuNPs (2) PAN nanofibers with 3 wt \% CuNPs (3) PAN nanofibers with 5 wt $\%$ CuNPs

In this study, two categories of solutions (pure PAN solutions and PAN/CuNPs solutions) were prepared. Firstly, 9 wt. \% of PAN was dissolved in DMF and stirred using a magnetic stirrer device at $85^{\circ} \mathrm{C}$ and $1200 \mathrm{rpm}$ for an hour so as to obtain homogenized solutions. The solutions were designated as pure PAN solutions in this paper. In the second category, the copper nanoparticles (1, 3 and $5 \mathrm{wt}$ \%) was added into the previous PAN/DMF solutions, respectively.

\subsection{Characterization of nanofibers}

For SEM analysis of nanofibers produced from four different PAN solutions, the nanofibers were first coated with a thin gold layer by electrodeposition method and then the nanofibers were examined using SM Zeiss LS-10 microscope. XRD analysis was measured from $10^{\circ}$ to $90^{\circ}$ for $2 \theta$ and at the scanning speed of $5 \% \mathrm{~min}$ with a Bruker D8 X-ray diffractometer equipped with a $\mathrm{Cu} \mathrm{K} \alpha$ anode $(\lambda=1.541 \AA)$. The contact angle measurement device (Dataphysics instruments $\mathrm{GmbH}$, model OCA15 Pro, version 1.3) was used to analyze the hydrophobicity of nanocomposites fibers. To do so, a dosing volume of $2 \mu \mathrm{L}$ of water was used at $0.5 \mu \mathrm{L} / \mathrm{s}$ as dosing rate. Thermal 
degradation of PAN and PAN doped 1 wt.\% copper nanofibers up to $900^{\circ} \mathrm{C}$ was investigated by TGA analysis. For this, the nanofibers were heated at $0-900^{\circ} \mathrm{C}$ with a heating rate of $10^{\circ} \mathrm{C} / \mathrm{min}$ in a nitrogen atmosphere. EC values of PAN and PAN doped 1 wt.\% copper nanofibers were measured using a four point probe device (ENTEK Elk. FPP-460 with Pt probes) at room temperature. The glass translation temperatures, crystallization peak temperatures and melting point temperature of PAN and PAN doped $1 \mathrm{wt}$. \% copper nanofibers were determined by DSC analysis.

\section{Results and Discussion}

The scanning electron microscopy (SEM) was performed to examine the morphology of the as-spun nanofibers). Figure 2 presents the SEM images and the graphs of nanofiber diameter distribution of the as-spun pure PAN fibers and PAN/Cu fibers with different copper nanoparticles percentage of mass contents $(1,3$ and $5 \mathrm{wt}$. $\%$ ) produced at $15 \mathrm{kV}$, respectively. As can be seen in the Figure 2, taken together by adding copper nanoparticles in the electrospinning solution did not affect negatively the morphology of the as-spun composite nanofibers. Like in the case of pure PAN solutions, most of electrospinning solutions containing copper nanoparticles had the fabrication of beads-free and uniform composite fibers. However, for the fibers obtained with electrospinning solution containing $1 \% \mathrm{Cu}$, homogeneous fibers with a narrower diameter distribution were found to be closer to each other. As the copper concentration in the solution increased, the diameter distribution ranges increased and fibers with different diameters were obtained. In addition, no agglomeration of copper nanoparticles was observed on the surface of the nanofibers. When the diameter of $\mathrm{PAN} / \mathrm{Cu}$ nanofibers were compared to that of pure PAN nanofibers, it was determined that PAN nanofiber average diameter containing $1 \% \mathrm{Cu}$ had the lowest and most homogeneous diameter distribution. In this study the average diameters of fibers were $327.19 \mathrm{~nm}$ for pure PAN fibers and $271 \mathrm{~nm}, 362.5 \mathrm{~nm}$ and $306.26 \mathrm{~nm}$ for PAN/Cu nanofibers containing 1,3 and 5 wt. \% of copper nanoparticles, respectively. A rotational viscometer (JK$\mathrm{RV}-1$ ) was used to analyze the viscosity of the electrospinning solutions with and without copper nanoparticles. The dynamic viscosity of the solutions (also known as absolute viscosity) was found to be 462.5 mPa.s for pure PAN (9 wt. \%) and 577.7, 3160.25 and $11526.66 \mathrm{mPa} . \mathrm{s}$ for electrospinning solutions containing 1,3 and 5 wt. \% Cu, respectively. As can be seen in Figure 3a-c, the marked observation to emerge from the graph investigation is that the viscosity of the solutions increased with an increase of copper nanoparticles contents. As expected, nanofibers with more uniform distribution were obtained with an increase of dynamic viscosity. However, in this study, the diameter distribution was non-uniform when more than $1 \% \mathrm{Cu}$ was added [19]. Figure $3 b$ reports the variation of the mean diameter distributions of nanofiber against the dynamic viscosity of the solution. In this study the average diameters of fibers were $327.19 \mathrm{~nm}$ for pure PAN fibers and $271 \mathrm{~nm}, 362.5$ $\mathrm{nm}$.

The EC of the pure PAN fibers and fibers containing copper nanoparticles was examined by using the fourpoint probe technique. The results are compared in Figure 3a. The EC values were $5.81 \times 10^{-3} \mathrm{~S} / \mathrm{cm}$ for pure PAN nanofibers and $1.38 \times 10^{-2}, 8.69 \times 10^{-2}$ and $4.43 \times 10^{-3} \mathrm{~S} / \mathrm{cm}$ for nanofibers containing (1, 3 and 5 wt. \%) of copper nanoparticles percentage of nanofiber mass contents, respectively. As can be seen in Figure 3, higher EC were obtained at low copper nanoparticles contents (1 wt. \%). It is worth noting that PAN nanofibers with $1 \mathrm{wt} \%$ of copper performed at $15 \mathrm{kV}$ present a $137.52 \%$ increase in the value of EC compared to pure PAN nanofibers. However, in 5 wt. \% of copper nanoparticles contents, nanofibers presented an EC lower than that of pure PAN nanofibers. Results show that the EC value decreases beyond the dynamic viscosity value of $577.7 \mathrm{mPa}$.s. Therefore, in this study, the dynamic viscosity value of $577.7 \mathrm{mPa}$.s could be taken as the optimum dynamic viscosity value for EC of PAN fibers containing copper nanoparticles.

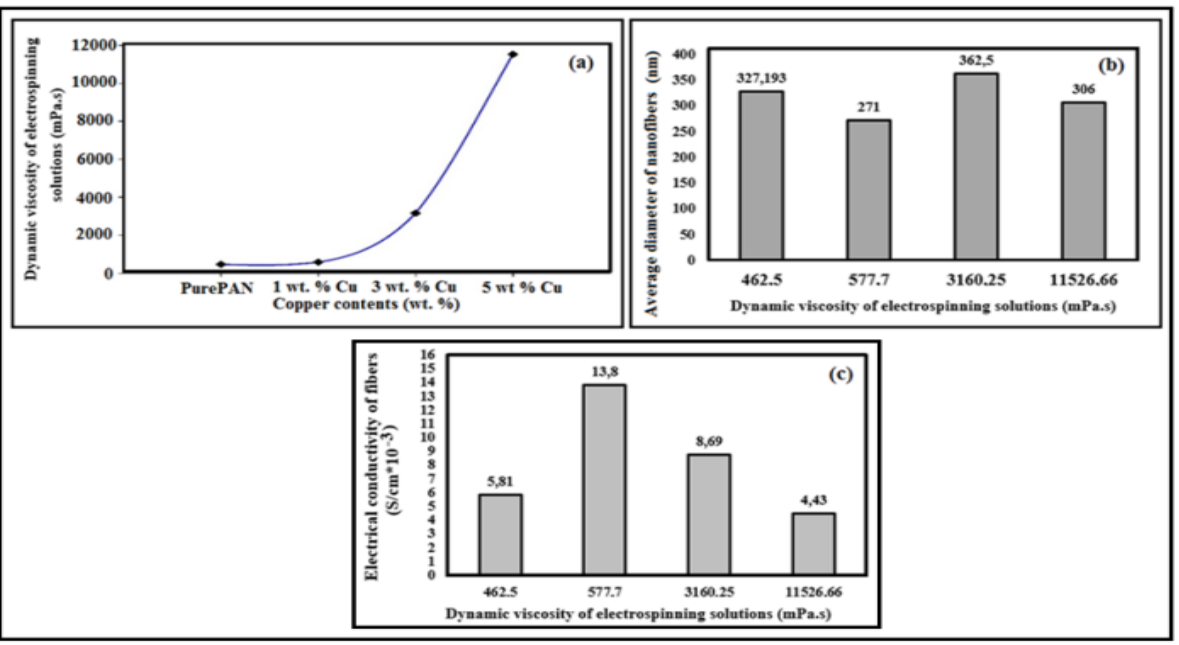

Figure 2. SEM images and diameter distributions of pure PAN and PAN nanofibers with $\mathrm{Cu}$ (a) pure PAN nanofibers (b) PAN nanofibers with 1 wt $\%$ $\mathrm{Cu}$, (c) PAN nanofibers with 3 wt $\% \mathrm{Cu}$, (d) PAN nanofibers with $5 \mathrm{wt} \% \mathrm{Cu}$ 


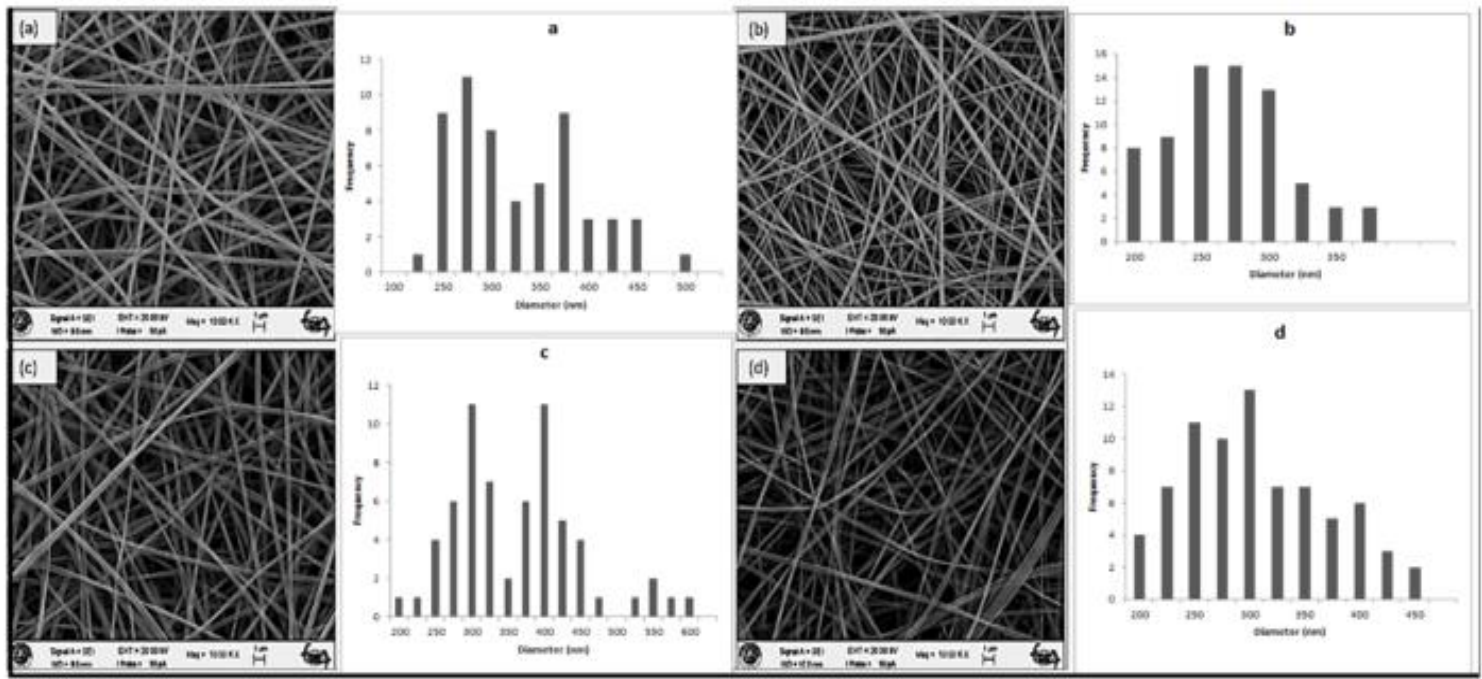

Figure 3. (a) Variation of dynamic viscosity of the solutions in function of copper nanoparticles contents (pure PAN 1,3 and $\% 5$ wt of CuNPs), (b) variation of average diameters against dynamic viscosity (mPa.s) of the solutions (c) variations of EC of nanofibers against dynamic viscosity (mPa.s) of the solutions. In (a) and (b) from left bar to right bar : pure PAN 1, 3 and 5 wt \% of CuNPs, respectively

The dispersion of small amount (1 wt. \%) of copper nanoparticles in the solution not only has led to a decrease of the average diameter of the as-spun nanofibers but also to the highest value of EC. The variation of EC of PAN fibers containing copper nanoparticles was summarized in the Table 1. In order to have an idea of the range of our results, in the Table 1, different results of this study were compared to the literature ones. To the best of our knowledge, the investigation of EC of PAN nanofiber containing copper has not yet been examined before. XRD was performed to give detailed information on the structure of crystalline samples and to confirm the phase composition of the as-spun nanofibers. According to the literatures, two peaks appear around $2 \theta=17^{\circ}$ and $2 \theta=29^{\circ}$ for the pure PAN. The peak associated with (100) plane of a orthorhombic semi-crystalline PAN structure appeared at $2 \theta=17^{\circ}$ for pure PAN fibers [30, 31].

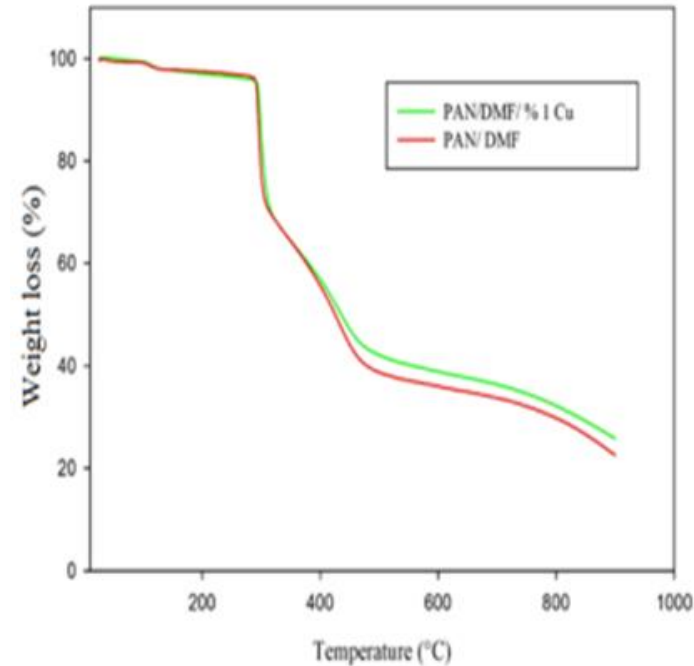

(a)

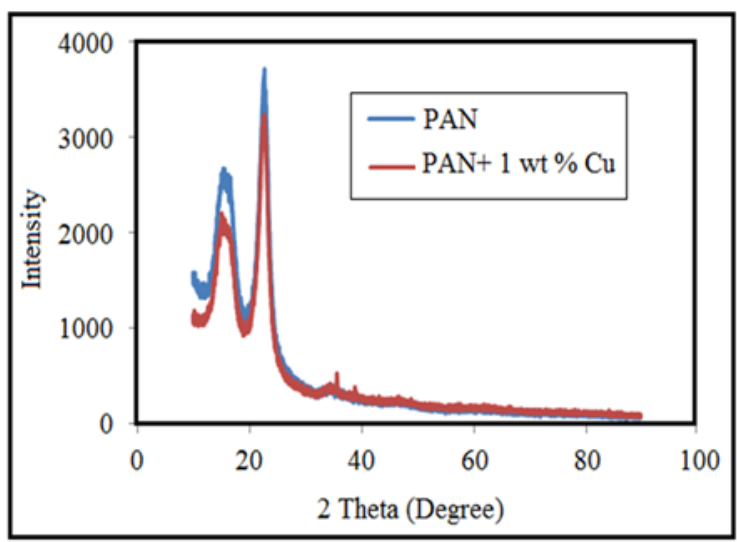

Figure 4. XRD patterns of pure PAN and PAN/CuNPs

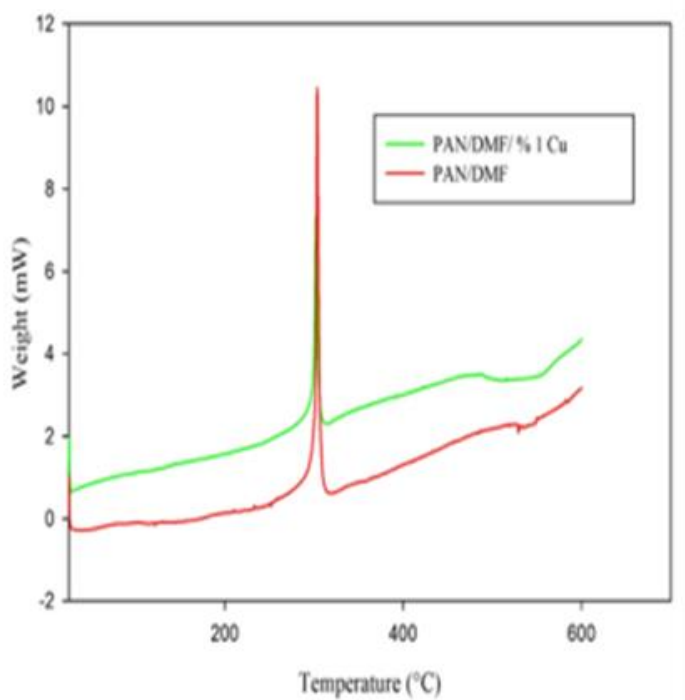

(b)

Figure 5. (a) TGA (b) DSC pattrens of pure PAN and PAN/CuNPs nanofibers 
As can be seen in Figure 4, two peaks were found for either nanofibers sample. The first broad peak is located at around $2 \theta=16^{\circ}$, which represents the x-ray reflection of the (100) plane in PAN [32] and reveals the amorphous state of materials. The second peak which was sharper than the first one was found at around $2 \theta=23^{\circ}$ and reveals the crystalline structure of the materials. Furthermore, such peaks do not make any significant shifts but it was observed a decrease of the relative intensity of peaks when $\mathrm{Cu}$ nanoparticles were added in the electrospinning solution [33]. Although two small peaks were found at around $2 \theta=36^{\circ}$ and $2 \theta=39^{\circ}$ for samples containing copper nanoparticles, it can hardly be attributed to copper nanoparticles due to the fact that a closer inspection revealed that the positions of these peaks are different to those of pure copper nanoparticles. The decrease in the PAN peak intensity indicates that CuNPs were successfully incorporated and homogeneously dispersed in the material matrix [34].

Thermogravimetric analyzer (TGA) and differential scanning calorimetry were employed in order to study the thermal behavior of the as-spun nanofibers. Figure 5a and Figure 5b show the TGA-DTA and DSC patterns of pure PAN and PAN/CuNPs nanofibers, respectively. The investigation revealed that there are striking similarities between pure PAN and PAN/Cu nanofibers decomposition process. The TGA thermograms of pure PAN nanofibers showed $\% 77.2$ of weight loss for samples obtained from $15 \mathrm{kV}$ as electrospinning voltage. And their respective amount of waste materials were \% 22.8 by mass after reaching $900{ }^{\circ} \mathrm{C}$. PAN-doped PAN nanofiber shows a mass loss of $75 \%$ up to $900{ }^{\circ} \mathrm{C}$. The amount of waste at $900{ }^{\circ} \mathrm{C}$ was determined as $25 \%$. As can be seen in Table 2, weight loss values of PAN/Cu fibers were less than those of pure PAN fibers. Therefore, inorganic residuals values were higher than those of pure PAN fibers after reaching $900{ }^{\circ} \mathrm{C}$. What is more, comparing the onset temperatures of the resultant nanofibers a slight enhancement of the thermal stability was observed with the addition of $1 \mathrm{wt} \%$ of copper nanoparticles. These results confirm the existence of nanoparticles in the as-spun nanofibers.

Calculation of the composite fiber content can be done by three different methods. This calculation can be done according to the titration method, optical microscopy related techniques, resin burning method and TGA analysis. After the formation of PAN fibers, the amount of nanoparticle in the fiber content and the amount of matrix PAN were calculated from TGA. TGA thermograms of weight loss as a function of temperature at $100-450{ }^{\circ} \mathrm{C}$ for the neat PAN [35].

The component content of the as-spun composite fibers was calculated according to the Equation 1 [31] and the weight content data were presented in Table 2.

PAN content $\%=\frac{\text { Composit fiber } \% \text { decomposition }-\mathrm{Cu} \% \text { decomposition }}{\text { PAN pure } \% \text { decomposition }-\mathrm{Cu} \% \text { decomposition }}$

The glass translation temperatures of pure PAN fiber was $112^{\circ} \mathrm{C}$. An endothermic peak of the glass transition temperature was not observed in the $1 \mathrm{wt}$. \% copper-doped PAN nanofiber. Meanwhile, the DSC thermogram revealed that the crystallization peak temperatures of composite fibers and fiber containing $1 \mathrm{wt} \% \mathrm{Cu}$ were observed at $300{ }^{\circ} \mathrm{C}$ and $305{ }^{\circ} \mathrm{C}$ for fibers obtained from $15 \mathrm{kV}$, respectively. In addition, the melting point temperature of composite fibers was found to be $560{ }^{\circ} \mathrm{C}$. Melting point increased by $20{ }^{\circ} \mathrm{C}$ with the addition of copper. The DSC related data are presented in Table 3.

EDX analysis images of PAN nanofibers with $1 \mathrm{wt} \%$, $3 \mathrm{wt} \%, 5 \mathrm{wt} \% \mathrm{Cu}$ nanoparticles are presented in Figure $6 \mathrm{a}, \mathrm{b}, \mathrm{c}$. TEM images of $\mathrm{Cu} / \mathrm{PAN}$ nanofibers are shown in Figure 6d-e. The presence of copper nanoparticles from the existing atomic contents of nanofibers has been proven.

Surfaces providing water contact angle lower than $90^{\circ}$ are considered as hydrophilic. However, when contact angles higher than $90^{\circ}$, surfaces are regarded as hydrophobic and surfaces presenting a contact angle higher than $150^{\circ}$ are designed as super-hydrophobic [3639].
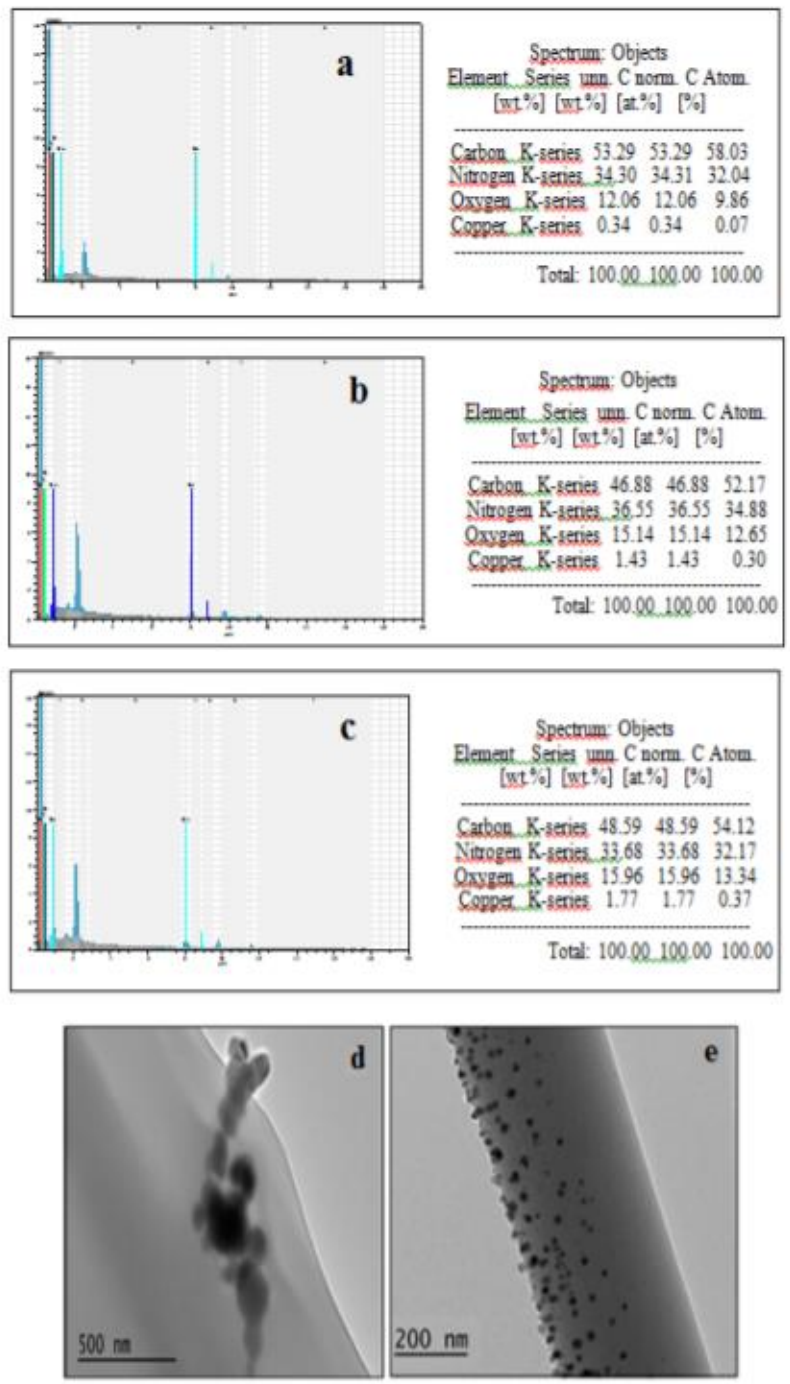

Figure 6. EDX and TEM images of $\mathrm{Cu} / \mathrm{PAN}$ nanofibers (a) PAN nanofibers with 1 wt $\%$ CuNPs (b) PAN nanofibers with $3 \mathrm{wt}$ $\%$ CuNPs (c) PAN nanofibers with 5 wt \% CuNPs d-e) TEM images of $\mathrm{Cu} / \mathrm{PAN}$ nanofiber

In this study, only nanofibers samples which presented the highest values of EC were picked out for hydrophobicity investigation. Therefore, the static contact angles of fibers containing 1 wt. $\%$ of copper nanoparticles were investigated. 
Table 1. Comparison of EC values for nanofibers/nanofibers with nano particules [40]

\begin{tabular}{|c|c|c|c|}
\hline Chemicals & $\begin{array}{c}\text { Electrical } \\
\text { conductivity }(\mathrm{S} / \mathrm{cm})\end{array}$ & References & Comments \\
\hline Pure PAN in DMF & $5.81 \mathrm{E}^{-03}$ & This study & Nanofibers produced at $15 \mathrm{kV}$ \\
\hline $\mathrm{PAN} / \mathrm{DMF} / \mathrm{Cu}$ & $1.38 \mathrm{E}^{-02}$ & This study & Nanofibers produced at $15 \mathrm{kV}$ \\
\hline Pure PAN in DMF & $0.2-0.5$ & {$[20]$} & $\begin{array}{l}\text { EC of the pure PAN nanofiber changed with the } \\
\text { carbonization temperature }\end{array}$ \\
\hline Pure PAN in DMF & $6.8 \mathrm{E}^{-03}$ and 1.96 & [21] & Carbonized at 700 and $1000^{\circ} \mathrm{C}$, respectively \\
\hline Pure PAN in DMF & 1.42 & [22] & Carbonized at $1000^{\circ} \mathrm{C}$ \\
\hline Nylon-6 with polyaniline & 1.3 & [23] & $\begin{array}{c}\text { Polymerization technique. Randomly oriented } \\
\text { nanofiber membrane fiber }\end{array}$ \\
\hline $\begin{array}{l}\text { Polypyrrole }\left[\mathrm{PPy}\left(\mathrm{SO}_{3} \mathrm{H}\right)-\right. \\
\text { DEHS] }\end{array}$ & $2.7 \mathrm{E}^{-02}$ & [24] & $\begin{array}{c}\text { Not blending. Randomly oriented nanofiber } \\
\text { membrane fiber. }\end{array}$ \\
\hline $\begin{array}{l}\text { Poly(L-lactide) with } \\
\text { polyaniline }\end{array}$ & 0.3 & [25] & Randomly oriented nanofiber membrane fiber \\
\hline $\begin{array}{l}\text { Polyvinyl alcohol with Nafion } \\
\qquad(1: 5)\end{array}$ & $1.7 \mathrm{E}^{-02}$ & [26] & Randomly oriented nanofiber membrane fiber \\
\hline $\begin{array}{l}\text { Poly(methyl methacrylate) } \\
\text { with } 2 \text { wt. } \% \text { multi-walled } \\
\text { carbon nanotube }\end{array}$ & $5.3 \mathrm{E}^{-04}$ & [27] & Blending technique. Single fiber \\
\hline $\begin{array}{l}\text { Silk membrane coated with } \\
\text { multi-walled carbon nanotube }\end{array}$ & $2.4 \mathrm{E}^{-04}$ & [28] & $\begin{array}{l}\text { Surface coating by dipping in carbon nanotube } \\
\text { suspension.Randomly oriented nanofiber } \\
\text { membrane fiber }\end{array}$ \\
\hline $\begin{array}{l}\text { Polyethylene oxide with } \\
\text { polypyrrole coating }\end{array}$ & $1 \mathrm{E}^{-03}$ & [29] & $\begin{array}{c}\text { Surface polymerization. Randomly oriented nanofiber } \\
\text { membrane fiber }\end{array}$ \\
\hline $\mathrm{PAN} / \mathrm{DMF} / \mathrm{SiO}_{2}$ & $8.26 \mathrm{E}^{-03}$ & [41] & Nanofibers produced at $15 \mathrm{kV}$ \\
\hline
\end{tabular}

The contact angle measurement results revealed that nanofibers containing $1 \mathrm{wt}$. \% of copper nanoparticles showed a hydrophobic behavior. As illustrated in Figure 7 , there was a slight difference between both contact angle values of composite nanofibers. It is important to note how the hydrophobic behavior of nanofibers (pure PAN and PAN/ 1 wt. \% Cu fibers) surfaces was improved in both cases by adding $1 \mathrm{wt} \%$, from $120.18^{\circ}$ to $124.93^{\circ}$. To the light of these results, the surfaces of the as-spun fibers were found to be hydrophobic. It is thought that the increase in surface contact angle of copper doped and PAN fibers is due to the increase of roughness on the fiber surface.

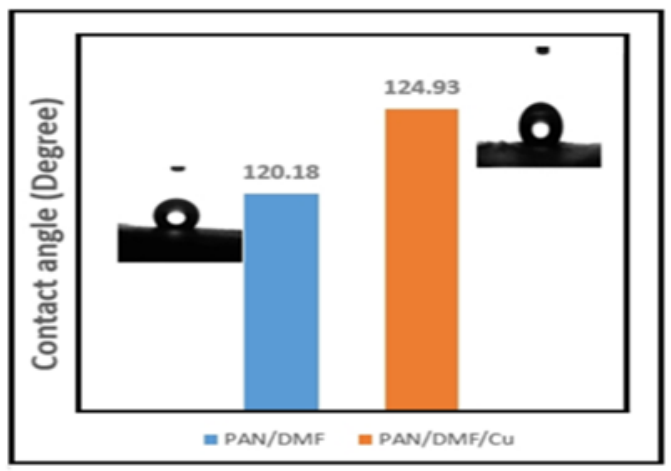

Figure 7. Average static contact angles of the as-fabricated pure PAN and PAN/Cu fibers

Table 2.TGA data and weight content (\%) of pure PAN and PAN/Cu composite fibers

\begin{tabular}{|c|c|c|c|c|c|c|c|}
\hline \multirow[t]{2}{*}{ Fibers } & \multirow{2}{*}{$\begin{array}{l}\text { IDT } \\
\left({ }^{\circ} \mathrm{C}\right)\end{array}$} & \multirow{2}{*}{$\begin{array}{l}\underset{\left({ }^{\circ} \mathrm{C}\right)}{\operatorname{Max} \mathrm{T}_{\mathrm{d}}} \\
\end{array}$} & \multirow{2}{*}{$\begin{array}{c}\mathrm{T}_{5} \\
\left({ }^{\circ} \mathrm{C}\right)\end{array}$} & \multirow{2}{*}{$\begin{array}{l}\mathrm{T}_{9 \text { or }} \mathrm{T}_{10} \\
\left({ }^{\circ} \mathrm{C}\right)\end{array}$} & \multirow{2}{*}{$\begin{array}{l}\text { Residual weight at } 900^{\circ} \mathrm{C} \\
(\%)\end{array}$} & \multicolumn{2}{|c|}{$\begin{array}{c}\text { Fibers } \\
\text { Weight content }(\%)\end{array}$} \\
\hline & & & & & & $\mathrm{Cu} \%$ & PAN $\%$ \\
\hline $\begin{array}{l}\text { Pure PAN } 150000 \mathrm{~g} / \mathrm{mol} \\
(15 \mathrm{kV})\end{array}$ & 290 & 295 & 293 & 298 & 23 & - & 100 \\
\hline $\begin{array}{c}15 \mathrm{kV} \\
\text { PAN/Cu }(\% 1)\end{array}$ & 290 & 300 & 265 & $310 \mathrm{~T}_{10}$ & 25 & 1.8 & 98.2 \\
\hline
\end{tabular}

Max. $\mathrm{T}_{\mathrm{d}}$ - maximum decomposition temperature, IDT- Initial decomposition temperature, $\mathrm{T}_{5}-5 \%$ weight decomposition, $\mathrm{T}_{9 \text { or }} \mathrm{T}_{10^{-}}-10 \%$ weight decomposition

Table 3. DSC data of PAN/Cu composite fibers for $15 \mathrm{kV}$

\begin{tabular}{|c|c|c|c|}
\hline $\begin{array}{c}\text { Composite } \\
\text { fibers }\end{array}$ & $\begin{array}{c}\text { Tg }\left({ }^{\circ} \mathbf{C}\right) \\
(\mathrm{Tg} *=(104.9 \\
\left.{ }^{\circ} \mathrm{C}\right)\end{array}$ & $\begin{array}{c}\mathbf{T c}_{(\text {exo })} \\
\left({ }^{\circ} \mathbf{C}\right)\end{array}$ & $\mathbf{T m}_{(\text {endo) }}\left({ }^{\circ} \mathbf{C}\right)$ \\
\hline PAN & 112 & 301 & 540 \\
\hline PAN/Cu (\%1) & - & 300 & 560 \\
\hline
\end{tabular}




\section{Conclusion}

In this study, pure PAN fibers and composite nanofibers containing 1,3 and $5 \mathrm{wt}$. \% of copper contents were successfully prepared by using electrospinning technique. The effect of copper nanoparticles on the morphology and diameters of composite fibers was investigated. It was found that fibers with smaller diameters were obtained with the decrease of copper contents in the solution. In addition, both pure PAN nanofibers and composite fibers were beads-free, uniform and without agglomeration of copper nanoparticles on the surface of the as-spun nanofibers. The EC of the as-spun fibers was investigated in terms of the copper contents. With the addition of \% $1 \mathrm{wt}$. of copper nanoparticles, the EC of the obtained fibers increased, however, it was observed that as the copper content increased the EC decreased. In this study, the highest conductivity was obtained with $\% 1$ wt. $\mathrm{Cu} / \mathrm{PAN}$ fibers obtained by electrospinning solution having a dynamic viscosity value of $577.7 \mathrm{mPa}$.s. The contact angle results revealed that the addition of $1 \mathrm{wt} \%$ of copper nanoparticles enhanced slightly the hydrophobic behavior of the composite fibers.

\section{Acknowledgements}

Authors acknowledged a financial support received from the research fund of the Selcuk University under Grant No. BAP 17201017.

\section{References}

[1] Wang, C., Du, J., Wang, S., Li, Y., Chen, X., Jing, X., Wei, Y., Preparation of silver nanoparticles dispersed in polyacrylonitrile nanofiber film spun by electrospinning, Materials Letters 59, 3046-3049, 2005.

[2] Mazinani, S., Ajji, A., Dubois, C., Morphology, structure and properties of conductive PS/CNT nanocomposite electrospun mat, Polymer, 50: 3329-3342, 2009.

[3] Sichani, G.N., Morshed, M., Amirnasr, M., Abedi, D., In situ preparation, electrospinning, and characterization of polyacrylonitrile nanofibers containing silver nanoparticles, Journal of Applied Polymer Science, 116, 1021-1029, 2010.

[4] Jeong, L., Park, W.H., Preparation and characterization of gelatin nanofibers containing silver nanoparticles, International Journal of Molecular Sciences, 15, 68576879, 2014.

[5] Huang, Z.M., Zhang, Y.Z., Kotaki, M., Ramakrishna, S., A review on polymer nanofibers by electrospinning and their applications in nanocomposites, Composites Science and Technology, 63, 2223-2253, 2003.

[6] Li, D., Xia, Y., Electrospinning of nanofibers: reinventing the wheel?, Advanced Materials, 16, 1151-1170, 2004.

[7] Shi, X., Zhou, W., Ma, D., Ma, Q., Bridges D., Ma, Y., Hu, A., Electrospinning of nanofibers and their applications for energy devices, Journal of Nanomaterials, Volume 2015, 20 pages, 2015.

[8] Ding, B., Yu, J., Electrospun nanofibers for energy and environmental applications, Springer, 2014.

[9] Ramakrishna, S., An introduction to electrospinning and nanofibers, World Scientific, 2005.

[10] Frenot A., Chronakis, I.S., Polymer nanofibers assembled by electrospinning, Current Opinion in Colloid \& Interface Science, 8, 64-75, 2003.[11] Karakaș, H., Electrospinning of Nanofibers and There Applications, Istanbul Technical University, Textile Technologies and Design Faculty, 2015.

[12] Fong, H., Chun, I, Reneker, D., Beaded nanofibers formed during electrospinning, Polymer, 40, 4585-4592, 1999.

[13] McKee, M.G., Wilkes, G.L., Colby, R.H., Long T.E., Correlations of solution rheology with electrospun fiber formation of linear and branched polyesters, Macromolecules, 37, 1760-1767, 2004.

[14] Tański, T., Matysiak, W, Hajduk, B., Manufacturing and investigation of physical properties of polyacrylonitrile nanofibre composites with $\mathrm{SiO}_{2}, \quad \mathrm{TiO}_{2}$ and $\mathrm{Bi}_{2} \mathrm{O}_{3}$ nanoparticles, Beilstein Journal of Nanotechnology, 7, 1141-1155, 2016.

[15] Rujitanaroj, Po., Pimpha, N., Supaphol, P., Preparation, characterization, and antibacterial properties of electrospun polyacrylonitrile fibrous membranes containing silver nanoparticles, Journal of Applied Polymer Science, 116, 1967-1976, 2010.

[16] Luoh, R., Hahn, H.T., Electrospun nanocomposite fiber mats as gas sensors, Composites Science and Technology, 66, 2436-2441, 2006.

[17] Deng, C., Gong, P., He, Q., Cheng, J., He, C., Shi, L., Zhu D., Lin T., Highly fluorescent TPA-PBPV nanofibers with amplified sensory response to TNT, Chemical Physics Letters, 483, 219-223. 2009.

[18] Wang, X., Lin, T., Needleless electrospinning of nanofibers: Technology and applications, CRC Press, 2013.

[19] Lee, D.Y., Kim, B.Y., Lee, S.J., Lee M.H., Song Y.S., Lee, J.Y., Titania nanofibers prepared by electrospinning, Korean Physical Society, 48 (6), 1686-1690, 2006.

[20] Ra, E.J., An, K.H., Kim, K.K., Jeong, S.Y., Lee, Y.H., Anisotropic electrical conductivity of MWCNT/PAN nanofiber paper, Chemical Physics Letters, 413, 188-193, 2005.

[21] Kim, C., Kim, J.S., Lee, W.J., Kim, H.S., Edie, D.D., Yang, K. S., Preparations of PAN-based Activated Carbon Nanofiber Web Electrode by Electrostatic Spinning and Their Applications to EDLC, Journal of the Korean Electrochemical Society, 5, 117-124, 2002.

[22] Panapoy, M, Dankeaw A., Ksapabutr, B., Electrical conductivity of PAN-based carbon nanofibers prepared by electrospinning method, Thammasat Int. J. Sc. Tech., 13, 11-17, 2008.

[23] Hong, K.H., Oh, K.W., Kang, T.J., Preparation of conducting nylon- 6 electrospun fiber webs by the in situ polymerization of polyaniline, Journal of Applied Polymer Science, 96, 983-991, 2005.

[24] Chronakis, I.S., Grapenson, S., Jakob., A., Conductive polypyrrole nanofibers via electrospinning: electrical and morphological properties, Polymer, 47, 1597-1603, 2006.

[25] Dong, H., Prasad, S., Nyame, V., Jones, W.E., Submicrometer conducting polyaniline tubes prepared from polymer fiber templates, Chemistry of Materials, 16, 371373, 2004

[26] Laforgue, A., Robitaille, L., Mokrini, A., Ajji, A., Fabrication and characterization of ionic conducting nanofibers, Macromolecular Materials and Engineering, 292, 1229-1236, 2007.

[27] Sundaray, B., Choi, A., Park, Y.W., Highly conducting electrospun polyaniline-polyethylene oxide nanofibrous membranes filled with single-walled carbon nanotubes, Synthetic Metals, 160, 984-988, 2010.

[28] Kang, S.J., Kocabas, C., Ozel, T., Shim, M., Pimparkar, N., Alam, M. A., Rotkin, S.V., RogersJ. A., High-performance electronics using dense, perfectly aligned arrays of single- 
walled carbon nanotubes, Nature Nanotechnology, 2, 230236, 2007.

[29] Nair, S., Natarajan, S., Kim, S.H., Fabrication of electrically conducting polypyrrole-poly (ethylene oxide) composite nanofibers, Macromolecular Rapid Communications, 26, 1599-1603, 2005.

[30] Chhatbar, M.U., Meena, R., Prasad, K., Siddhanta, A.K., Agar/sodium alginate-graft-polyacrylonitrile, a stable hydrogel system, Indian Journal of Chemistry, 48A, 10851090, 2009.

[31] Rajendran, S., Kannan, R, Mahendran, O., Study on Li ion conduction behaviour of the plasticized polymer electrolytes based on polyacrylonitrile, Materials Letters, 48: 331-335, 2001.

[32] Zussman, E., Chen, X., Ding, W., Calabri, L., Dikin, D.A., Quintana J.P., Ruoff, R.S., Mechanical and structural characterization of electrospun PAN-derived carbon nanofibers, Carbon, 43, 2175-2185, 2005.

[33] Robinson, J.W., Frame, E.S, Frame II, G.M., Undergraduate instrumental analysis, CRC press, 2014.

[34] Mohamed, S.A., Al-Ghamdi, A., Sharma, G., El Mansy, M.K., Journal of Advanced Research, 5, 79-86, 2014.

[35]Khan, W.S, Ceylan, M., Jabarrania, A., Saeednia, L., Asmatulu, R., Chemical and thermal investigations of electrospun polyacrylonitrile nanofibers incorporated with various nanoscale inclusions, Journal of Thermal Engineering, 3, 1374-1389, 2017.

[36] Lafuma, A., Quéré, D., Superhydrophobic states, Nature Materials, 2, 457-460, 2003.

[37] Yuan, Y., Lee, T.R., Contact angle and wetting properties, Surface Science Techniques, Springer, 3-34, 2013.

[38] Liu, Y., Chen, X., Xin, J., Super-hydrophobic surfaces from a simple coating method: a bionic nanoengineering approach, Nanotechnology, 17 (13), 3259-3263, 2006.

[39] Gao, L., McCarthy, T.J., A perfectly hydrophobic surface $(\theta \mathrm{A} / \theta \mathrm{R}=180 / 180)$, Journal of the American Chemical Society, 128, 9052-9053, 2006.

[40] Mpukuta, O.M., Investigation of electricalconductivity of nanofibers (PAN) containing nanoparticles (graphene, copper,silica) produced by electrospinning method,Selcuk University Graduate School of Natural And Applied Sciences, Master of Science Thesis, Department of Mechanical Engineering M.Sc.

[41] Mpukuta, O.M., Dincer, K., Erdal, M.O., Investigation of electrical conductivity of PAN nanofibers containing silica nanoparticles produced by electrospinning method, Materials Today: Proceedings, 18 (5), 1927-1935, 2019. 